\section{A constituição do campo psiquiátrico: duas perspectivas antagônicas}

\author{
The formation of the \\ field of psychiatry: two \\ opposing perspectives
}

Jairo Roberto de Almeida Gama

Pesquisador do Núcleo de Assessoria, Treinamento e Estudos em Saúde/Universidade Federal de Juiz de Fora; professor de psiquiatria da Faculdade de Ciências Médicas e Saúde de Juiz de Fora. Rua Vereador Sadi Carnot, 105 36021-620 - Juiz de Fora - MG - Brasil jairogama@gmail.com

Recebido para publicação em julho de 2010. Aprovado para publicação em abril de 2011.
GAMA, Jairo Roberto de Almeida. A constituição do campo psiquiátrico: duas perspectivas antagônicas. História, Ciências, Saúde - Manguinhos, Rio de Janeiro, v.19, n.1, jan.-mar. 2012, p.139-155.

Resumo

Analisa duas concepções antagônicas sobre a constituição do campo psiquiátrico. A perspectiva prevalente no Brasil, a foucaultiana, é contrastada com a perspectiva de Gauchet e Swain. Para a tarefa são abordadas duas obras de Foucault, $A$ história da loucura e $O$ poder psiquiátrico, e a obra de Gauchet e Swain, Madness and democracy. Propõe que as concepções de base sobre o que é e como se construiu o campo teórico psiquiátrico definem as estratégias políticas e assistenciais de uma sociedade na sua relação com a loucura. Aponta as consequências diversas que essas abordagens trazem para a reforma psiquiátrica brasileira.

Palavras-chave: constituição da psiquiatria; saúde mental; Michel Foucault (1926-1984); história da loucura; Brasil.

\section{Abstract}

The article analyzes two opposing views of the formation of the psychiatric field: the Foucauldian perspective, which holds sway in Brazil, and the perspective of Gauchet and Swain. Two works by Foucault (History of Madness and Psychiatric Power) are contrasted with Madness and Democracy, by the latter authors. It is argued that a society's political and assistance strategies about madness are shaped by the conceptual bases defining what constitutes the field of psychiatric theory and how it was formed. The article calls attention to the diverse consequences that these two approaches may have on the reform of Brazilian psychiatry.

Keywords: formation of psychiatry; mental health; Michel Foucault (1926-1984); history of madness; Brazil. 
A constituição do saber psiquiátrico, a forma como esse saber se organiza diante do sofrimento mental concreto dos indivíduos e as propostas de reforma assistencial pública estão diretamente relacionadas. A maneira como pensamos essas relações definem posições, muitas vezes divergentes, sobre a mente, a tipificação das pessoas e a concepção do diagnóstico, com consequências no debate público, nas proposições de políticas sanitárias e nos modelos teórico-assistenciais diversos. É possível afirmar que as concepções de base sobre o que é e como se construiu o campo teórico psiquiátrico definem as estratégias políticas, clínicas e assistenciais de uma sociedade na sua relação com a loucura.

Existem duas versões principais e antagônicas sobre a constituição do saber psiquiátrico: a proposta por Michel Foucault (2005) e a proposta por Marcel Gauchet e Gladys Swain (1999). As duas apresentam pontos de vista que se opõem. A descrição foucaultiana considera a captura da loucura pela psiquiatria uma perda, uma violência discursiva e institucional que transformou a experiência trágica, mas significativa para a humanidade, da percepção de uma doença. Gauchet e Swain, por sua vez, descrevem a abordagem alienista como tendo oferecido uma nova possibilidade de lidar com esse fenômeno e um ganho clínico no cuidado aos portadores de sofrimento mental. As visões opostas são produzidas por descrições alternativas de um mesmo objeto, a psiquiatria, e são produtos de uma dada configuração histórica visando determinados fins.

A abordagem da obra de Gladys Swain e Marcel Gauchet (1999), como contraposição à de Foucault (2005), não é nova no Brasil. Alguns estudiosos acreditam que a primeira oferece uma visão diferente e mais esclarecedora sobre a psiquiatria, em virtude das acuradas lentes conceituais e históricas que apresenta e que produz uma perspectiva tão significativa quanto a de Foucault (Bezerra Júnior,1992; Freitas, 2004; Serpa Júnior, 1996). Consideram que Foucault deixou de lado aspectos históricos relevantes, reduzindo a clínica inaugurada por Philippe Pinel a uma interrupção sofisticada do diálogo com a loucura. Por outro lado, outros autores criticam essa valorização do texto de Gauchet e Swain. Para Rodrigues (2007), por exemplo, estaria havendo uma 'domesticação' da experiência da reforma psiquiátrica brasileira, quando se empreende uma análise crítica da História da loucura (2005). A obra foucaultiana é descrita como uma "declaração de guerra a todos os reformismos psiquiátricos". Qualquer forma de produção discursiva ou de projeto clínico é considerada alguma forma de "colonização sobre a loucura" (Rodrigues, 2007, p.48).

A concepção foucaultiana, nesses termos, entende a intervenção clínica como uma forma de vigilância, clausura e empobrecimento subjetivo. Segundo o outro ponto de vista, a experiência que o campo clínico permite é diretamente responsável pela possibilidade de inventar novas maneiras de lidar com o sofrimento. Essas diferentes concepções e suas repercussões em um campo em plena efervescência política evidenciam a necessidade de retomar as obras em foco.

Neste artigo faço uma leitura crítica de duas obras de Foucault, $A$ história da loucura (2005) e $O$ poder psiquiátrico (2006) mostrando como o autor constrói uma visão da psiquiatria como projeto de exclusão, e apresento o livro de Gauchet e Swain, Madness and Democracy (1999) como um ponto de vista alternativo sobre o nascimento da psiquiatria como projeto revolucionário. Minha intenção é reabrir o debate sobre o tema e apontar as consequências clínicas, políticas e éticas de ambas as abordagens. 


\section{A psiquiatria como projeto de exclusão}

Foucault publica seu monumental A história da loucura em 1961, como trabalho de conclusão de seu doutorado em filosofia. O livro, que causou enorme impacto sobre o mundo acadêmico e profissional, é um marco crítico dos estudos sobre a loucura e fornece as bases para o pensamento contestatório antimanicomial. O trabalho é descrito pelo próprio autor como um estudo que se "coloca sob a luz da grande pesquisa nietzschiana, e que [ele] gostaria de confrontar as dialéticas da história com as estruturas imóveis do trágico" (Foucault, 2005, p.143). ${ }^{1}$ Considerando que a loucura ocupa um lugar na estrutura trágica, ele pretende mostrar a dinâmica desse processo, o percurso das mudanças históricas que aprisionaram a experiência trágica do louco. Antes signo da Queda do Homem, marca da morte em vida, a loucura foi posteriormente reduzida ao que do homem era embrutecimento, degradação em animalidade, até ser finalmente transformada em doença. Para Foucault, a razão iluminista criou uma forma ainda mais insidiosa de opressão e controle ao tornar patológica uma experiência humana fundamental. A seu ver, a loucura, antes de ser captada pelo discurso iluminista, ocupava um lugar significativo no imaginário social, pois dizia uma verdade sobre a humanidade.

Um aspecto interessante do seu trabalho é que, se por um lado, Foucault pretende estudar a operação que a razão clássica realizou sobre a loucura ao transformá-la em desrazão, por outro busca mostrar a lógica econômico-social que produziu o encarceramento dos loucos. Existe, portanto, certa tensão entre duas explicações sobre a mudança no trato com a loucura.

Quanto a sua crítica ao racionalismo, o autor salienta ter ocorrido uma captura, uma distorção de uma vivência pela redução dela a um outro vocabulário, a uma tradução forçada de um pensamento por outro. Perdendo a vivacidade dessa experiência, perde-se o contato com um aspecto fundamental da humanidade. Foucault explica que, na Idade Média, a lepra dominava o imaginário coletivo quanto às representações da morte e da punição divina. Quando essa doença finalmente desapareceu, em razão do isolamento dos doentes e da ausência de contato com focos da doença no Oriente, sobraram centenas de leprosários, lugares de exclusão e isolamento social. O imaginário coletivo elegeu, então, outra figura de punição e exclusão, a doença venérea, que apesar de ocupar por curto espaço de tempo a mesma posição social e institucional da lepra, não pôde assumir o seu lugar como representação da punição divina porque, desde o início, era vista como doença médica, a despeito da ressonância religiosa e moral que suscitava. Assim, do século XIV ao XVII o leprosário teve que esperar por uma 'nova representação do mal' capaz de ocupá-lo. É, portanto, nessa representação de um poder maléfico, ou melhor, nesse signo da Queda do Homem, permanentemente presente no horizonte da experiência humana, que Foucault identifica a estrutura ocupada sucessivamente por conteúdos imaginários diversos.

Na Idade Média a preocupação com a morte era central para a vida coletiva, vista de um ponto de vista teológico que aponta o pecado e sua punição. O tema era pregnante no imaginário e marcava todas as relações sociais. Os loucos de então eram apenas figuras sociais marginais, e a loucura, que não constituía um símbolo específico na relação com Deus, ocupava um lugar discreto na 'hierarquia dos vícios', o de polo oposto à prudência. 
No final da Idade Média ocorreu uma substituição do tema da morte pelo da loucura, e esta ganhou uma relação estreita com o nada, o vazio da existência. A loucura passou a assumir características diversas, sendo representada na literatura, na filosofia e na pintura. Começaram a ser delineadas duas formas antagônicas de pensamento sobre a loucura. Uma, na pintura, construiu uma experiência trágica da loucura; a outra, na literatura e filosofia, esboçou uma consciência crítica. São leituras opostas com relação à experiência do desatino. Na experiência trágica, a loucura fascina a imaginação porque representa um saber sobre o fim do mundo, o castigo divino e a queda humana. Assim, a preocupação com a morte, com as pestes e guerras, sofreu uma inflexão para a morte ainda em vida da loucura. Na consciência crítica construída na mesma época, a loucura passou a significar a fraqueza dos homens, suas ilusões, suas falsas ciências, sua presunção risível. Produto de uma visão humanista nascente, ela mostrava outra forma do Mal, não mais relacionada ao fim dos tempos, mas apenas ao 'erro e defeito'. Essa diferença entre os elementos trágico e crítico da loucura instaurada no século XV tornou-se cada vez mais pronunciada, com foco maior no polo crítico. O desatino era encarado como sátira moral, vista não mais como tragédia, mas como condição risível, objeto de sarcasmo da sociedade. Nesse deslizamento de sentido, converteu-se de objeto de fascínio em objeto de ironia. A consciência trágica da loucura perdeu sua potência imaginária e desapareceu, ou foi ocultada, no século XVI, em prol da consciência crítica. Foucault (2005) aponta esse movimento como a virada crucial na experiência da razão com relação à loucura, a qual, tornando-se "uma forma relativa à razão" (p.30), joga a experiência cósmica da loucura nas sombras. A consciência crítica faz da loucura uma das formas ou um elemento da razão, uma de suas potencialidades inerentes. Portanto, como elemento deslocado da própria razão, a loucura se vê conjurada, limitada em sua potência exterior à razão. ${ }^{2}$

O segundo aspecto da transformação social da loucura concerne ao momento econômico europeu. No século XVII os loucos passaram a ser internados junto com uma massa indiferenciada de todo tipo de marginais, em uma ordem econômica e social em pleno processo de mutação. A loucura, na Época Clássica, foi silenciada e retirada de circulação, num processo denominado por Foucault (2005) Grande Internação. Vemos que, agora, ele desloca o foco da análise para a economia capitalista como causa da exclusão.

Foucault escreve que esse fenômeno da internação se iniciou em toda a Europa ainda no século XV, em consequência das guerras religiosas, e atingiu seu ápice no século XVII. Um grande número de artesãos desempregados, camponeses desterrados e doentes, incapazes de se sustentar devido às guerras e ao enfraquecimento da economia, afluiu para as cidades, nelas gerando caos e miséria. Iniciaram-se então a captura e internação forçada em casas de detenção. Uma grande massa dessa mão de obra sem trabalho, empobrecida e sem amparo social foi recolhida. As oscilações do capitalismo marcaram o maior ou menor número de pessoas internadas, fazendo com que as estruturas de internação cumprissem papel significativo na sociedade, ao encarcerar os pobres, oferecer mão de obra barata nos tempos de pleno emprego, aprisionar indivíduos sem trabalho quando havia escassez na oferta de serviços e evitar revoltas.

Com a criação dos hospitais gerais, o processo de exclusão se consolidou. Eram locais não médicos, semijurídicos e administrativos, com poder de prisão, correção e castigo, 
destinados a recolher todos os pobres da cidade. Essa estrutura foi criada por ordem monárquica, em aliança com a burguesia francesa da época, e visava recolher todos aqueles que não podiam trabalhar. Era, portanto, "uma instituição totalitária onde reinam as leis do universo concentracionário, mas sem tecnologia hospitalar específica" (Castel, 1978, p.65). ${ }^{3}$ Embora existissem duas concepções simultâneas sobre o cuidado com os loucos, uma médica e outra correcional, eles passaram a ser internados no século XVII, independentemente de qualquer concepção de tratamento ou cura. Faziam parte de uma parcela discernível da sociedade, aqueles que não trabalhavam ou perturbavam a ordem pública.

Para Foucault, no século XVII a compreensão da loucura estava dividida em duas formas: uma dada pela exclusão do internamento, sob alegação de que seria uma variação do desatino, e outra dada pelo discurso médico recorrendo-se a uma nosologia incipiente. Entre essas formas de entendimento havia pouca semelhança ou pontos de apoio. Os loucos eram reconhecidos pela marca do desatino que portavam, pura negatividade e oposição à razão, e não pela descrição positiva de uma doença. Tal situação começou a mudar no século XVIII, com a construção de um saber positivo sobre a loucura, por meio de sua objetificação; antes de se constituir plenamente como ciência, esboçou-se um campo de racionalidade.

Segundo Foucault, a psiquiatria que se constituiu no final do século XVIII, durante o período revolucionário francês, com seu projeto igualitário embasado na cidadania plena, baseou-se na composição de duas demandas, a jurídica e a social. Rose (2006, p.120) mostra que o asilo conciliava "a obrigação constitucional de justificar legalmente todo constrangimento exercido sobre a liberdade dos cidadãos, com a obrigação social de internar aqueles que não haviam infringido qualquer lei mas derrogavam suas obrigações morais de cidadãos". ${ }^{4}$ A construção da doença mental foi feita sobre essa síntese, que concilia o dever de isolar e a necessidade de discernir a capacidade jurídica do indivíduo, e que constitui a base da futura "psicopatologia com pretensões científicas" (Foucault, 2005, p.133).

O século XVIII conheceu um aumento do número de internos nas casas de correção, assim como uma percepção social de que a loucura estava crescendo na sociedade, provavelmente, como diz Foucault, mais pela importância que adquiriram as 'doenças dos nervos' e as histerias, do que pela alienação mental. ${ }^{5}$ Inúmeras casas particulares foram criadas, como a pensão Belhomme e as várias Petites-maisons, transformadas em asilos para alienados. Na Inglaterra surgem os lunatic hospitals e também pavilhões em hospitais comuns. Esses hospitais, embora não fossem locais médicos, apontam uma mudança fundamental, pois começaram a separar a loucura de outras formas do desatino, dandolhe uma característica e uma percepção próprias, que estabeleceram uma ligação mais forte com o internamento. A partir de então, a psiquiatria começou a ganhar um contorno mais preciso, em que médicos deram início a uma teoria sobre o que passou a ser visto como doença mental, propondo uma forma de tratamento moral e um local para tratar os loucos, os asilos. O trabalho teórico e prático de Pinel é considerado, por Foucault, produto do cientificismo que assinala a consequência final do projeto redutor da experiência trágica da loucura.

Outra importante obra de Foucault (2006) é O poder psiquiátrico, compilação das aulas por ele ministradas no Collège de France de novembro de 1973 a fevereiro de 1974. Nela, o 
autor historiciza a psiquiatria na sua relação com a loucura, em continuidade a seus estudos sobre a constituição do saber psiquiátrico, mas estrutura sua pesquisa em novas bases. Antes, sua preocupação era com uma 'arqueologia do silêncio', a forma como o saber psiquiátrico organizou-se sobre uma estrutura de exclusão da loucura, no pensamento e no campo social. Foucault, na História da loucura (2005), mostrou como a percepção da loucura pelos indivíduos variou, originando formas de exclusão diversas. Além disso, tratavase de uma história das instituições asilares e de como ela se articula com o saber em construção. Agora, em vez do estudo das representações, Foucault investiga as estratégias discursivas e não discursivas em jogo na instituição. Sua ênfase recai sobre o poder, isto é, o papel que o poder tem na constituição de um saber, e também como esse poder é disseminado, como se estrutura e organiza e que efeitos causa no indivíduo. Sua intenção, ao estudar a psiquiatria, é também política, parte de um projeto mais amplo de questionar as bases do poder disciplinar na sociedade: "No domínio da psiquiatria ... parece-me interessante saber como se instauraram o saber psiquiátrico, a instituição psiquiátrica, no inicio do século XIX, ... se quisermos lutar agora contra todas as instâncias de normalização" (p.457). Faz, portanto, do estudo da psiquiatria um exercício de um combate intelectual que visa a tudo o que, na sua concepção, mantém a sociedade sob controle.

Foucault parte de críticas que ele próprio faz a sua História da loucura, afirmando ter utilizado "fechaduras enferrujadas" para analisar a psiquiatria (Foucault, 2006, p.18). A primeira crítica concerne à ideia de violência como força desregrada, irregular; o filósofo entende, agora, que a violência se dá pelo poder disseminado e calculado sobre os corpos. A segunda crítica que faz a si mesmo é sobre a ideia de instituição em si, que substitui pelas "disposições de poder, as redes, as correntes, as intermediações, os pontos de apoio, as diferenças de potencial" (p.20), estes sim constitutivos do indivíduo e da coletividade. Questiona também a ideia de que o modelo familiar introduzido por Pinel e Jean-Étienne Esquirol foi um fator de violência. Enfim, é por meio de uma microfisica do poder que Foucault pretende prosseguir em sua análise, mais do que da instituição, da família ou da violência.

Nas 12 aulas, Foucault apresenta detalhadamente como se estrutura o poder psiquiátrico, exercido por meio da ordem disciplinar. Mostra que o nascimento da psiquiatria é correlativo a uma organização institucional que exercerá controle absoluto sobre os corpos dos internos. Aponta como o enquadramento numa ordem rígida é a fonte do tratamento. O poder, nesse momento, é difuso, microfísico, constante, baseado numa rede dispersa em inúmeros pontos de apoio. Uma 'disposição tática' de diferentes indivíduos, organizados para fazer funcionar a instituição, possibilita que se exerça o poder.

Foucault (2006) caracteriza esse esforço 'panóptico' como uma luta, uma guerra contra a loucura, isto é, contra uma força que o louco porta e que é necessário dominar. Define essa força como força pura (a do indivíduo furioso); força das paixões sem limite (a da mania sem delírio); força que abala as idéias (a da mania); e força que marca intensamente uma idéia particular (a da melancolia ou da monomania). É um esforço de domínio sobre essa força descontrolada que, para Foucault, caracteriza a psiquiatria e fundamenta a ordem disciplinar.

O teórico afirma que essa forma de tratamento se colocava contra o modelo clínico ou medicamentoso. A psiquiatria nasce, digamos, na direção contrária ao restante da medicina. 
Foucault (2006) chama a atenção para a abordagem da loucura que o tratamento moral instaura, pois não coloca como objetivos primeiros a observação, o diagnóstico e a definição da terapêutica, mas sim o enfrentamento e o domínio da loucura. Para ele, os discursos científicos que sustentavam a psiquiatria, ou seja, o discurso clínico nosológico e o discurso anatomopatológico e localizacionista, na prática não exerciam nenhum efeito. A psiquiatria asilar se colocava ao abrigo desses discursos ao legitimar sua prática, mas não fazia deles instrumentos operacionais no tratamento dos alienados. E o saber do psiquiatra era, apenas, um elemento de poder do dispositivo disciplinar asilar.

Outro aspecto importante é ressaltado por Foucault (2006). Nos primórdios do tratamento moral havia todo um jogo de verdade do delírio, implicado na terapêutica. Montavam-se para os alienados cenas cuja função era fazer o delírio se misturar à realidade. Tentava-se autenticar o delírio aceitando-o numa encenação em que o interno 'reconhecia' medidas salvadoras que o haviam livrado da perseguição, do envenenamento ou da punição delirante. Era uma estratégia de cura baseada numa verificação fictícia da realidade do delírio. Há relatos de cura efetuados por meio dessas manobras, por exemplo, na clínica de Pinel, auxiliado por Jean-Baptiste Pussin. Por outro lado, no início do século XIX foi suprimida essa tentativa de infundir realidade no delírio por meio de aproximações sucessivas, comparações e distinções da verdade e do erro. A vigilância disciplinar e a punição impediriam qualquer tipo de manejo de idéias errôneas. O psiquiatra do século XIX tornouse um fator de "intensificação do real" (p.164), exercendo um sobrepoder da realidade e expulsando de vez o erro. Nesse sentido, ele age de forma oposta ao psiquiatra nos primórdios do alienismo, que pode ser descrito como um "contrabandista do real" ou o "mestre ambíguo"(p.163) da realidade, como vemos nas manobras cênicas de Pinel.

A terapia psiquiátrica por volta de 1840 contentava-se em estabelecer um padrão que combinava isolamento no asilo; prescrição de algumas medicações, como éter e láudano; disciplina rígida quanto à organização do tempo - de trabalho, sono e alimentação, por exemplo -; e punição de qualquer ato contrário às regras, que se dava na forma de aparelhos de contenção como duchas, cadeira giratória etc. Todo tipo de pressão sobre o interno seria efetuado para abalar a crença equivocada e fazer com que a verdade aparecesse e o doente reconhecesse seu erro. A confissão, diz Foucault (2006), é o momento da cura. Nota-se, então, que a psiquiatria muda o enfoque do tratamento no decorrer dos seus primeiros vinte anos de existência; voltarei ao assunto adiante.

A eficácia da 'máquina asilar' deve-se, segundo Foucault (2006), às seguintes determinações: enquadramento disciplinar ininterrupto; dissimetria de poder entre médico e interno; jogo da necessidade, do dinheiro e do trabalho; e autorreconhecimento por meio de uma linguagem que fala a verdade de sua identidade institucional.

A primeira tarefa do alienista é desequilibrar o jogo do poder, mostrando quem tem o domínio, instaurando uma dissimetria cuja função é quebrar a onipotência subjacente a toda loucura e promover a docilidade do alienado. A linguagem é vigiada, é importante a forma como o doente utiliza os nomes na sua relação com a hierarquia asilar e, fundamentalmente, o papel que a linguagem tem na disciplina, no uso correto do que foi aprendido. A segunda tarefa consiste em instaurar uma série de necessidades, com o objetivo de tornar presente a realidade, de introduzir a concretude da vida no mundo da loucura. Todos são 
obrigados a trabalhar. Se não o fazem, não recebem qualquer dinheiro e, portanto, passam a sofrer algumas carências. O trabalho possui, assim, várias funções: promover disciplina, ordem, regularidade, mas também a remuneração necessária para que o interno saia de um estado de carência criado pelo asilo - uma evidência de que ele não é onipotente como pensa. Além disso, a carência, como diz Foucault (2006), mostra para o alienado que o exercício da loucura tem um certo preço. E a principal carência do asilo é a carência de liberdade.

Por fim, a tarefa fundamental, a de fazer com que o interno diga a verdade, que não fale de seu delírio, suas alucinações, ainda que essa verdade seja dita sob coação. O ponto fundamental é que o alienado abdique de falar o que é factualmente falso. Ao lado disso, é importante que ele se vincule à sua própria história, que se reconheça na sua identidade, mesmo que à força. Em resumo, exige-se que o louco confesse a verdade sobre si mesmo, mas uma verdade histórica e não a vivência subjetiva que possui dessa história. A cura, nessa perspectiva, é a aceitação de um poder e a obediência a uma norma.

Foucault (2006) analisa o sistema disciplinar no asilo sobre um pano de fundo mais geral. O poder disciplinar, em toda a sociedade, teve uma primeira função no século XVIII: "ajustar a multiplicidade dos indivíduos aos aparelhos de produção ou aos aparelhos de Estado que os controlam, ou ainda, ajustar o princípio do acúmulo de homens à acumulação do capital" (p.137). Porém, devido ao funcionamento ótimo do sistema gerar anomalias e irregularidades nas suas margens, é preciso criar instituições que absorvam os excluídos do processo - o asilo, por exemplo. Essas instituições, por seu turno, serão uma nova fonte de lucro e poder para a burguesia do século XIX.

$\mathrm{O}$ asilo, portanto, se inscreve em um processo de busca de lucro, abordado por Foucault em análise sobre as instituições privadas, em contraposição às públicas. Nas primeiras, predomina o modelo familiar, ao passo que nas outras o sistema funda-se sobretudo no controle e na produção de bens e serviços pelo trabalho. Há, então, duas maneiras de lidar com a disciplina no asilo, assim como duas maneiras de gerar lucro: uma baseada na exploração, outra, nos valores familiares. As casas de saúde particulares funcionariam sobre bases diversas das públicas, como se fossem uma espécie de sobrefamília, isto é, uma família ideal que assume uma função 'ortopédica' na correção do indivíduo, até devolvê-lo ao seu verdadeiro seio familiar. Para realizar esse trabalho há um pagamento apropriado, e a esse respeito novamente Foucault lança mão do esquema explicativo econômico para explicar o manicômio. Não é mais uma mudança de mentalidade forjada pelo dispositivo disciplinar, mas o sistema econômico utilizando o manicômio como receita para a burguesia incipiente e o asilo ajustando os indivíduos ao sistema capitalista.

A partir de 1850, diz Foucault (2006), essa situação se inverte: o louco passa a ser visto como uma criança, sendo possível nesse momento introduzir a idéia de que um modelo familiar é necessário para o tratamento. O autor afirma que "houve duas idades da psiquiatria. Uma em que se utilizavam correntes e outra, ao contrário, em que se utilizaram, digamos, os sentimentos de humanidade" (p.135). A medicina mental consegue, enfim, se impor como especialidade, por intermédio de uma articulação entre três fatores: a colocação em evidência, isto é, a produção de uma percepção mais fina da alienação mental, em lugar da pouca diferenciação que havia antes; a instauração de um estabelecimento para 
tratamento dessa alienação, visto como único lugar adequado e eficaz; e a montagem de uma ação terapêutica baseada na disciplina, o tratamento moral.

Algumas críticas às concepções foucaultianas desse momento podem ser feitas. Se é verdade que o esforço de domínio sobre uma força estava presente, não parece ter sido esse o objetivo principal. Foucault parece confundir fins com meios, distorcendo o que estava em jogo para os alienistas. O domínio era o fundamento do tratamento moral, não o objetivo final. É também um engano não notar que o esforço nosológico ganhava terreno, e a preocupação em observar e realizar o diagnóstico era um dos objetivos dos alienistas, no intuito de fazer avançar seu novo conhecimento (Bercherie, 1989). Alguns autores, como Leuret $(2005)^{6}$, mostram isso claramente. Basta observar sua preocupação em distinguir as diversas causas da alienação. E, de fato, ele aplica a distinção nosológica que embasa tratamentos distintos em duas mulheres com melancolia, uma de causa orgânica, outra de causa 'moral'.

Além disso, podemos aceitar que o tratamento asilar se inseria em um sistema econômico e era, ele também, gerador de lucros - aliás, como em outras épocas. Mas daí a afirmar que esse sistema produziu a mentalidade dos homens que criaram locais de tratamento para a loucura há uma distância muito grande.

Por fim, Foucault propõe que a cura se baseava na dívida do alienado com o médico, o que funda uma sujeição à disciplina, motor da cura. Seu argumento é que a cura é utilizada como moeda a ser paga ao médico pela libertação. A dívida será paga de duas maneiras: com a sujeição e com a própria cura a que a sujeição disciplinar conduziu. Em resumo, o sujeito se cura porque ficou em dívida para com o médico. Apesar de engenhoso, o esquema foucaultiano tem o defeito de simplificar excessivamente a relação entre médico e paciente, com uma argumentação forçada. Por um lado, se o paciente se cura, ainda que seja por gratidão, não vejo por que haveria nisso um problema. Por outro, é possível realmente que o paciente se cure por gratidão? Ele agradeceria o reconhecimento de sua humanidade se curando? Basta o reconhecimento? Se basta, é interessante que a psiquiatria o tenha tentado; se não basta, a explicação deve ser outra, e não a que Foucault aponta.

Para Foucault (2006, p.222), a cura do indivíduo significa sujeição, pelo poder disciplinar, à realidade em quatro pontos: "a lei do outro, a identidade a si, a não admissibilidade do desejo, e a inserção da necessidade num sistema econômico". É possível dizer de outro modo: uma nova relação do sujeito com o outro da sociedade e da linguagem, uma possibilidade de ter uma identidade conforme a realidade que seja mais normativa, a assunção do desejo como responsabilidade do sujeito e a possibilidade de se inserir na vida econômica da sociedade.

\section{A psiquiatria como projeto revolucionário}

Como contraponto ao pensamento foucaultiano, Marcel Gauchet e Gladys Swain, no seu livro Madness and democracy: the modern psychiatric universe (Gauchet, Swain, 1999)7, apresentam o problema do asilo e do tratamento moral de outra maneira. Os autores pensam que Foucault se equivocou ao não evidenciar a verdadeira significação do surgimento do asilo, no contexto cultural mais amplo da invenção das sociedades 
democráticas. Além disso, ele teria criticado o mito pineliano sem considerar o impacto real de sua obra na constituição de uma racionalidade nova sobre a loucura. A obra de Gauchet e Swain busca dar novo significado ao nascimento da psiquiatria, enfatizando seu papel em um ideário revolucionário e valorizando a construção da clínica, porém sem cair na armadilha de fazer uma história hagiográfica nem escamotear a falência da instituição asilar, destinada ao fracasso no ato mesmo de sua constituição.

A remodelação da Salpêtrière em 1802 é considerada o marco do nascimento do asilo moderno, consequência de um projeto claro de implantar um local de cura dos alienados e não apenas de tratamento. Essa mudança é importante, porque indica uma confiança terapêutica sem precedentes. O objetivo, portanto, é ambicioso. Há uma mudança de racionalidade acerca da curabilidade da doença mental, cuja 'descoberta' é descrita por Pinel no seu livro Tratado médico-filosófico sobre a alienação mental ou a mania (Pinel, 2007). Ao contrário de Foucault, Gauchet e Swain (1999) pensam que o enfoque dado por Pinel no cuidado com os loucos foi, de fato, revolucionário. A mudança ocorre porque nasce a concepção de que a loucura é "acessível a partir do interior" (p.26). Pinel inverteu o postulado de que a loucura era na teoria incurável e na prática eventualmente curável; agora, a curabilidade era teoricamente possível e só na prática potencialmente incurável. A incurabilidade, antes de Pinel, era tida como certeza absoluta, e depois dele devia ser pensada como possibilidade, como ameaça ao paciente no horizonte do tratamento. Entretanto, o doente crônico ganhava a possibilidade teórica de a cura tornar-se alcançável pela terapêutica. Haveria sempre uma certa distância entre o sujeito louco e sua loucura, entre o eu e a doença, entre a razão e esse ponto desviante da própria razão, e tal distância era o que permitia o acesso do outro a sua subjetividade, por meio do discurso.

Conforme os autores, o Tratado de Pinel (2007) é fundamental, não só do ponto de vista teórico mas também político, porque possibilitou um novo campo de experimentação, ao testar suas ideias na prática e reunir, num só local, alienados que antes eram divididos entre curáveis (Charenton) e incuráveis (Salpêtriére, Bicêtre, Petites-maisons). Abandonase a ideia de que aqueles que não alcançassem a cura num prazo determinado seriam encaminhados para o simples confinamento. A possibilidade e a esperança de cura foram redefinidas, e todos os indivíduos alienados que chegavam à Salpêtrière seriam tratados sem tempo predeterminado para interrupção do esforço terapêutico. Nesse sentido, os autores afirmam que a história da psiquiatria se confunde com a decisão de "nunca pronunciar um paciente incurável, e então nunca interromper a comunicação e o tratamento. A história da psiquiatria é a história de uma vagarosa infusão de curabilidade dentro da incurabilidade" (Gauchet, Swain, 1999, p.42).

O que importa no novo enquadre é a abertura de um encontro, pela palavra, de dois sujeitos, em que um deles propõe-se a operar um resgate por meio da confrontação no outro do que nele está em contradição com sua própria razão. Portanto, há um sujeito cuja razão dividida precisa ser integrada, mediante um processo clínico que tem um outro como guia. Não mais alienação total, mas sim possibilidade de recuperação.

Nesse primeiro momento da invenção da psiquiatria houve um evidente otimismo terapêutico, uma crença radical na possibilidade de alcançar, pela fala e num ambiente humanizado, o núcleo de razão escondido sob os sintomas da alienação. Entretanto, 
apesar dos bons resultados obtidos na prática - Gauchet e Swain (1999) estimam que metade dos pacientes internados era curada com um ano de internamento -, a confiança nos recursos do tratamento moral foi rapidamente abalada. Os autores atribuem essa desconfiança à afirmação simples e direta de que toda loucura era curável. Faltaram elementos teóricos que demonstrassem cabalmente ser a loucura, por natureza, curável. Outro ponto fundamental para a descrença que começou a grassar entre os médicos foi a evidente cronicidade de muitos casos. O projeto pineliano tinha colocado a questão de maneira muito utópica, e gerou-se uma enorme decepção quando ele foi comparado ao objetivo grandioso a que se tinha proposto.

Gauchet e Swain (1999) apontam, também, outro fator crucial que mudou o enfoque do tratamento psiquiátrico logo após o seu nascimento: a inflexão quanto ao papel do asilo, dada por Pinel na reedição do seu Tratado. Ele transferiu o poder terapêutico do tratamento moral, antes fundado no relacionamento pessoal médico-paciente, para a ação sobre o coletivo, considerando a instituição, sua organização e disciplina a fonte da terapêutica. Pinel queria curar os alienados, e para isso engendrou o tratamento moral numa abordagem coletiva, no intuito de remodelar as personalidades doentes num esquema unificado, invariável e, supostamente, seguro, de acordo com o pensamento reformador da época. A questão era: como fazer para alcançar a parte do sujeito que está suficientemente sadia para tirá-lo da loucura? Que estratégia adotar, nessa tarefa? O asilo foi a solução. O tratamento moral foi delegado à instituição como um todo, resposta à incerteza de se alcançar o núcleo de razão na loucura do indivíduo por meio do encontro direto entre médico e louco e tentativa de exercer uma ação impessoal mas efetiva sobre a mente do alienado. Para os autores "algo como um segundo nascimento da psiquiatria é estabelecido na redefinição de manejo interno e de autoridade médica que Pinel traz à tona sob o ímpeto de sua recente experiência na La Salpêtrière" (p.46; grifos do original). Esse 'segundo nascimento' configurou uma psiquiatria institucional totalitária e excludente que marcou negativamente sua prática, após ter-se fundado intelectualmente a descoberta da curabilidade do doente mental. O tratamento moral foi transformado, a perspectiva do tratamento deslocou-se do indivíduo para o grupo, e o que o que cura é menos o médico e mais a instituição. A contradição do projeto pineliano reside em ter aberto a possibilidade de cura ao mesmo tempo que a fechou numa instituição - contradição que, hoje, talvez começa a ser superada.

Os autores argumentam que o asilo e o tratamento moral devem ser entendidos tendo como pano de fundo uma mudança na concepção de homem, característica da Idade Moderna. Eles mostram que o projeto pineliano era, na verdade, baseado num modelo emprestado do pensamento social mais amplo, cujo ideal era a organização de um espaço coletivo que deveria mudar o homem. O asilo não era um invento, mas sim mero espaço de aplicação de um plano social, em conformidade com uma ordem institucional ideal. A Revolução Francesa possibilitou a mudança de paradigma: a sociedade passou a ser considerada soberana e capaz de definir por si mesma a forma de se organizar, não mais baseada no poder divino que o rei encarnava, mas em suas próprias necessidades. O projeto de transformar a humanidade está na origem, portanto, das formas institucionais totais que moldou a constituição do asilo moderno, que é consequência da ideia revolucionária 
de que a sociedade não deve mais se referir a algum poder transcendente para escolher e construir o seu destino, é efeito da representação do homem como produto do processo social (Gauchet, Swain, 1999).

O tratamento dos loucos pode ser visto como produção de personalidades conformes à lei, isto é, como um experimento social tributário do momento revolucionário de transformação social, no qual o indivíduo deveria ser transformado pelo poder da coletividade. O louco, sendo aquele que perdeu a autonomia, deverá, a partir de então, ser tutelado integralmente, isolado da sociedade, para que seja possível o controle total sobre ele na busca da restituição de sua razão. O asilo é um experimento político na sua essência, sendo "a cristalização das formas mais avançadas de autoridade" (Gauchet, Swain, 1999, p.80).

Assim, a inflexão pineliana no tratamento moral é consequência desse entendimento mais geral de que a coletividade desempenha um papel central na constituição do sujeito. Apesar de manter a ideia original de que a comunicação com o indivíduo é a primeira tarefa do tratamento, o enfoque no coletivo alterou a forma de manejo do tratamento. A proposta asilar estava fadada ao fracasso pela falha estrutural do esquema proposto, pois a execução do modelo se baseava na ilusão de que o ser humano poderia estar sob controle absoluto, totalmente manipulado e gerido pelas estruturas de poder. Para Gauchet e Swain (1999), não há possibilidade teórica ou prática de absorver as individualidades numa massa com vistas a modificar profundamente as subjetividades, visto que o ambiente manipulado é intrinsecamente limitado na sua capacidade de transformar o outro. O mito da máquina pan-óptica serve como ilustração para nos darmos conta do devaneio a que se entregaram os reformadores sociais da época. Articula-se a ele outro mito, também bastante sedutor na conformação dessa mentalidade, o da massa, essa 'figura eminentemente política' que passou a ter um papel relevante na construção da idéia de cura pela instituição.

Gauchet e Swain (1999) marcam três momentos-chaves da história do tratamento psicológico da loucura. O primeiro é denominado momento pineliano e caracterizado pela descoberta de um resquício de razão na loucura, de uma contradição entre duas posições subjetivas do alienado, numa oposição que permite a ação clínica por meio da comunicação. O segundo momento é nomeado asilar. Durante ele a possibilidade de tratamento é projetada na instituição como espaço que privilegia a prática coletivista; baseiase na idéia de que a loucura pode ser curada pelo uso do aparato de poder, que desejava separar o louco de si mesmo, de sua individualidade aberrante, e misturá-lo ao pensamento normal da massa controlada. O terceiro momento é o psicanalítico, quando se evidencia a irredutibilidade da singularidade subjetiva e a incapacidade de tratar sem levar em conta o espaço psíquico indevassável do outro.

A maioria dos críticos e estudiosos da história da psiquiatria abordam a questão do asilo do ponto de vista exclusivamente segregador, seu papel violento e excludente para aqueles que se desviavam da norma e da razão burguesas. A questão central trazida por Gauchet e Swain (1999) é que o asilo, ao lado da descrição tradicional de seus efeitos de poder, teve efeito imprevisto sobre o entendimento social da loucura. Além de os autores mostrarem que o uso do poder tinha como pressuposto uma idéia mais ampla de transformação de homem, sendo o asilo um laboratório de reforma do humano, apontam também que a prática asilar mudou a visão que a sociedade tinha da loucura, pois 
possibilitou a percepção de que os loucos poderiam conviver com todos: os "asilos podem não ter tratado o alienado, mas mudaram a alienação" (p.100). Uma mudança de paradigma ocorreu, quanto à radical separação entre o louco e o outro. Antes, consideravase que o louco era por natureza isolado, ensimesmado, e consequentemente o confinamento era natural na sua condição; agora, ele era visto como fundamentalmente como um ser capaz de interagir.

A análise que os autores realizam sobre as mudanças na organização da vida asilar destaca a profunda mudança ocorrida na concepção da loucura. A substituição das celas individuais pelo dormitório coletivo, por exemplo, mostra o interesse de Pinel pela possibilidade de comunicação, se não entre o louco e o são, pelo menos entre os internos - daí a imersão num espaço coletivo de troca. Da mesma forma, o momento das refeições passa a ser valorizado. Questiona-se a alimentação fornecida aos indivíduos em suas celas, sem talheres e pratos adequados, e o refeitório ganha importância para a socialização dos pacientes. Nasce uma preocupação com a mesa compartilhada, a disposição e a relação dos comensais entre si, o conhecimento e a cordialidade que eles devem ter, as boas maneiras, a higiene, a educação. Apesar da preocupação exagerada com o comportamento dos doentes e a correção dos costumes - o que poderia ser avaliado de forma apressada como inculcação da moral burguesa e infantilização na aplicação de regras -, nota-se a ruptura operada nesse momento, a confiança na possibilidade de convivência, de inter-relação e comunicação com o outro, o enfoque nas conquistas civilizatórias, que não estariam perdidas.

Os alienistas começam a descrever o alienado como alguém capaz de obedecer aos contornos da realidade e empenhar-se em tarefas cotidianas. Essas preocupações, que são hoje triviais e poderiam ser vistas como tolices preconceituosas, não eram em absoluto evidentes na época. Foram, ao contrário, conquistas difíceis de um conhecimento em transformação e uma mudança enorme na concepção da loucura. Os alienistas estavam, inconscientemente, desmantelando a concepção do louco como outro absoluto, separado do mundo humano de forma intransponível. Porém, ainda que tenha mudado a concepção da loucura, a psiquiatria nascente mantém-se presa à ideia de que o espaço fechado do asilo é necessário para que se possa construir a conexão com o mundo interno do alienado. De um lado, "restaurou a potencialidade dos pacientes como sujeitos; de outro deixou-os completamente separados da possibilidade de relações casuais com pessoas comuns" (Gauchet, Swain, 1999, p.104).

Pode-se dizer então que, na visão dos autores, o asilo se construiu sobre uma miragem, a de remodelar o homem doente por meio de um controle total sobre seu comportamento. Entretanto, como efeito colateral produziu uma virada na concepção da loucura como outro radical, passando a alienação a ser vista como contingência da razão humana. Apesar da crítica ao asilo que, como os autores mostram, iniciou muito mais cedo do que se supunha, essa instituição se manteve como local único de tratamento, em virtude de a loucura manter, sob o aspecto da cronicidade, uma aura de 'estrangeiridade' dificilmente ultrapassável naquele momento.

A extrema ambiguidade do tratamento moral e do asilo é que, se por um lado exerceu um poder desmedido sobre o sujeito, por outro deu ao louco um lugar em que ele pudesse ser reconhecido como sujeito de sofrimento e, consequentemente, de cura. Na Época Clássica, 
o louco era reconhecido na sua completa externalidade em relação à razão e à sociedade. A loucura era 'aceita' por todos como aberração, animalidade exposta, atração monstruosa. A invenção da sociedade democrática e o nascimento da psiquiatria estabeleceram outra relação, no quadro da doença mental. Embora tenha gerado consequências estigmatizadoras, também estabeleceu uma abertura para a possibilidade de troca verbal e da compreensibilidade do outro. A dificuldade de cura efetiva levou à visão do asilo como uma 'máquina' transformadora de subjetividades, mas a marca da confiança na cura pelo encontro ficou como herança a ser redescoberta. O sistema que excluiu o louco para tratá-lo não se deu com a descoberta de outro radical, mas, ao contrário, com a obrigação democrática de descobrir a similaridade onde antes havia o estranho. A não exclusão do estranho, nas sociedades tradicionais, é possível porque o outro de fato não importa, aceita-se sua presença como um estrangeiro, não pertencente à coletividade; ele não é uma questão a ser pensada. O que vemos como exclusão, na verdade, pode ser visto como o início longo e penoso do processo de inclusão. A sociedade que cria a exclusão é aquela que, com rupturas políticas e culturais, exigirá a sua abolição.

\section{Considerações finais}

Nota-se similaridade entre as duas abordagens no que concerne à descrição da organização e dos efeitos do poder disseminado, coletivo e pan-óptico do asilo. Contudo, Foucault estrutura sua análise do poder como assujeitamento do outro ao sistema capitalista, ao passo que Gauchet e Swain propõem, para o segundo nascimento da psiquiatria, uma análise do poder como gestão coletiva do tratamento, produto da crença no poder de cura da instituição sobre o sujeito. Desse ponto de vista, em seus arcabouços argumentativos centrais, os dois sistemas de análise do nascimento da psiquiatria e do asilo se opõem frontalmente.

Para Foucault existe um 'estado selvagem' e uma 'pureza primitiva' na loucura ainda não aprisionada. A ideia, portanto, de uma natureza imutável, imemorial, tragédia reveladora da essência humana, está subjacente à concepção foucaultiana, especialmente na História da loucura. Foucault parece querer preservar a experiência trágica da loucura, uma representação social portadora de uma verdade que se revela ao desvelar os enganos da razão. Sua crítica dirige-se a todo tipo de controle social, de ortopedia moral e de objetivação do humano. Entretanto, ele parece supor uma experiência original da loucura, como se seu aspecto trágico não fosse uma representação social como qualquer outra, com as consequências positivas e negativas que qualquer forma descritiva sobre um fenômeno humano pode trazer. De fato, acreditar numa 'pureza original' da loucura é esquecer que a própria originalidade é produção discursiva - captura de um fenômeno, como bem mostrou Derrida (2001).

Quando Foucault faz o elogio da loucura trágica esquece que, de fato, existia um abismo simbólico na relação do louco com o não louco, cuja proximidade era similar à estabelecida com um animal ou um ser indecifrável. Esse abismo permitia todo tipo de atrocidade física e moral. A clínica da loucura, como apontam Gauchet e Swain (1999), criou a possibilidade do encontro pela palavra, embora houvesse a vigilância institucional. A ideia de resgatar um cidadão cuja razão está temporariamente afetada, mas não perdida, começou a ganhar 
sentido para a sociedade. A instituição asilar e o tratamento moral ganham, com tal abordagem, outra possibilidade de entendimento.

Noto que a crítica foucaultiana clássica à psiquiatria é muitas vezes considerada, por parte dos autores do amplo campo da reforma psiquiátrica brasileira, uma formulação inequívoca e isenta de contradições. Mostrei aqui que a leitura de outros autores aponta uma versão diferente do nascimento da psiquiatria. As consequências para a visão que temos do projeto clínico se altera radicalmente, se optamos por uma versão ou outra. Numa, a foucaultiana, a clínica psiquiátrica é redução e violência; noutra, a psiquiatria pode ser vista como instrumento de inclusão e responsabilização de um sujeito visto como igual, uma psiquiatria que reconhece sua historicidade, suas contradições e seus limites, mas aceita o desafio de alterar sua prática numa sociedade em transformação, o que a faz repensar sua própria racionalidade.

Poder-se-ia argumentar que a análise foucaultiana não leva necessariamente à contestação em bloco da psiquiatria, pois seria contraditório que um movimento que criou instituições, técnicas e teorias para tratar pessoas fosse também responsável pela redução delas a objetos de conhecimento e instrumentalização. Entretanto, ao levar o ponto de vista foucaultiano ao limite argumentativo, vê-se que a tensão nos textos analisados tem origem no pressuposto - mais evidente nos cursos de 1973 - de que o poder disciplinar que cria objetos de conhecimento gera um saber que está, desde o início, marcado pelo assujeitamento do outro. Na sua luta contra toda forma de clausura, Foucault acentua o caráter disciplinar e redutor do conhecimento, a normalização. Entretanto, parece-me que ao fazê-lo esmaece o aspecto produtor de sentido e as consequências libertárias, ressaltados por Gauchet e Swain (1999) quando analisam a constituição da psiquiatria, mas sem escamotear as dificuldades, as incoerências e os recuos que tinham sido apontados por Foucault.

Ressalte-se também que, embora se critique Foucault por sua abordagem unilateral do tema, sua obra continua sendo fundamental para a análise da psiquiatria contemporânea. Ele colocou em evidência que a prática discursiva de uma época produz efeitos políticos, clínicos e institucionais duradouros, produz verdades. Vemos hoje mudanças que indicam um rearranjo da teoria psiquiátrica com consequências imprevisíveis. Explicações causais fisicalistas baseadas em genética molecular, desenvolvimento de inúmeros psicofármacos e seu uso por larga parcela da população, descrição de fenômenos psicopatológicos com base em neuroimagem, uso de medicações para a melhora da performance social e ocupacional são fenômenos complexos e desafiadores que necessitam, para sua análise, teorias sobre discurso, poder e subjetividade. Foucault continua indispensável para os estudos, embora deva ser lido em perspectiva e de maneira crítica.

\section{NOTAS}

${ }^{1}$ Foucault explicita assim seu nietzschianismo: "Eu sou simplesmente nietzscheano e tento, à medida do possível, sobre um certo número de pontos, ver, com a ajuda de textos de Nietzsche - mas também com as teses anti-nietzscheanas (que são de certa forma nietzscheanas!), o que se pode fazer neste ou naquele domínio. Eu não busco nada mais, mas isto eu busco bem" (citado em Ferry, Renault, 1988, p.95).

${ }^{2}$ Uma crítica importante ao livro de Foucault é realizada por Derrida (2001), que entende o projeto de uma história da loucura como uma história da própria loucura, isto é, a loucura falando de si e não na 
linguagem da psiquiatria ou da razão. Uma vez que fazer isso é impossível, Foucault pretende realizar uma 'arqueologia' do silêncio a que a loucura foi submetida, e é justamente isso que Derrida considera 'louco' no projeto foucaultiano, uma vez que uma arqueologia já seria uma 'linguagem organizada'. Derrida também faz uma crítica histórica: se houve uma separação entre loucura e razão, ela não poderia ter-se dado na Idade Clássica, mas talvez no pensamento grego - cuja análise mereceria um trabalho cuidadoso de tradução de termos que equivaliam à loucura, como talvez a hubris grega. Derrida reconhece o trabalho revolucionário e monumental de Foucault, mas critica sua pretensão de realizar uma história 'da' loucura e uma arqueologia do silêncio. (Ver a resposta de Foucault a Derrida em Foucault, 1999).

${ }^{3}$ Segundo Castel (1978), o complexo hospitalar consistia de uma gama de instituições heterogêneas, que abrangia casas de detenção, hospitais de tratamento como os Hôtel-Dieu, depósitos de mendigos e dezenas de fundações de assistência, sendo Salpêtrière e Bicêtre suas estruturas mais importantes.

${ }^{4}$ Nesta e nas demais citações de textos em outros idiomas, a tradução é livre.

${ }^{5}$ Edward Shorter (1997) mostra que houve um aumento considerável de casos de alienação mental em decorrência do grande número de sifilíticos com alterações cerebrais, assim como em virtude de mais casos de alcoolismo e outras doenças relacionadas ao álcool, advindas com o aumento do consumo de bebidas na época.

${ }^{6}$ François Leuret (1797-1851) é considerado um dos precursores da terapia comportamental. Seguindo os passos de Esquirol, tentou estudar os fatos mentais do ponto de vista psicológico. Criou uma escola para pacientes que não sabiam ler ou escrever, organizou sessões de leitura e introduziu, no refeitório de Bicêtre, uma 'disciplina terapêutica', que proibia a presença de enfermeiros durante as refeições visando abolir o caráter autoritário e buscando 'ressocializar' os internos. É considerado um dos inventores do jeux de rôle, um tipo de jogo de associações linguísticas para a construção de um conto coletivo (Silva, 2005).

${ }^{7}$ O livro foi publicado na França com o título La pratique de l'esprit humain: l'instituition asilaire et la révolútion démocratique (Gauchet, Swain, 1980).

\section{REFERÊNCIAS}

BERCHERIE, Paul.

Os fundamentos da clínica: história e estrutura do saber psiquiátrico. Rio de Janeiro: Jorge Zahar. 1989.

BEZERRA JÚNIOR, Benilton.

Cidadania e loucura: um paradoxo? In: Bezerra Júnior, Benilton; Amarante, Paulo (Org.). Psiquiatria sem hospício: contribuições ao estudo da reforma psiquiátrica. Rio de Janeiro: Relume-Dumará. p.113-126. 1992.

CASTEL, Robert.

A ordem psiquiátrica: a idade de ouro do alienismo. Rio de Janeiro: Graal. 1978.

CAVALCANTI, Maria T.

A trama no tear: sobre o tratar em psiquiatria.

Tese (Doutorado) - Instituto de Psiquiatria, Universidade Federal do Rio de Janeiro, Rio de Janeiro. 1997.

DERRIDA, Jacques.

Cogito e história da loucura. In: Ferraz, Maria Cristina Franco (Org.). Três tempos da história da loucura. Rio de Janeiro: Relume Dumará. 2001.

FERRY, Luc; RENAUT, Alain.

Pensamento 68: ensaio sobre o anti-humanismo contemporâneo. São Paulo: Ensaio. 1988.
FOUCAULT, Michel.

O poder psiquiátrico. São Paulo: Martins Fontes. 2006.

FOUCAULT, Michel.

História da loucura na Idade Clássica. São Paulo: Perspectiva. 2005.

FOUCAULT, Michel.

Resposta a Derrida. In: Motta, Manoel Barros da (Org.). Ditos e escritos 1: problematização do sujeito: psicologia, psiquiatria e psicanálise. São Paulo: Forense Universitária. p.243-257.1999.

FREITAS, Fernando Ferreira Pinto de. A história da psiquiatria não contada por Foucault. História, Ciências, Saúde - Manguinhos, Rio de Janeiro, v.11, n.1, p.75-91. 2004.

GAUCHET, Marcel; SWAIN, Gladys. Madness and democracy: the modern psychiatric universe. Princeton: Princeton University Press. 1999.

GAUCHET, Marcel; SWAIN, Gladys. La pratique de l'espirit humain: l'institution asilaire et la revolution démocratique. Paris: Gallimard. 1980.

LEURET, François.

Indicações a seguir no tratamento moral da 
loucura. Revista Latinoamericana de

Psicopatologia Fundamental, São Paulo, v.3, n.3, p.540-553. 2005.

\section{PINEL, Phillipe.}

Tratado médico-filosófico sobre a alienação mental ou mania. Porto Alegre: Editora da UFRGS. 2007.

RODRIGUES, Heliana de Barrros Conde. Michel Foucault, as 'marcas da pantera' e a 'pantera cor-de-rosa': apontamentos sobre o processo de desinstitucionalização psiquiátrica. Vivência, Natal, n.32, p.41-60. 2007.

ROSE, Nikolas.

Foucault, Laing et le pouvoir psychiatrique.

Sociologie et Société, Quebec, v.38, n.2, p.113-131.
2006. Disponible sur: http://id.erudit.org/ iderudit/016375ar. Consulté en: 10 fev. 2012.

SERPA JÚNIOR, Octavio Domont.

Sobre o nascimento da psiquiatria. Cadernos Ipub, Rio de Janeiro, v.3, p.15-30. 1996.

SHORTER, Edward.

$A$ history of psychiatry: from the era of asylum to the age of Prozac. New York: John Wiley \& Sons. 1997.

SILVA, Marluce Maria de Godoy. Sobre François Leuret e sua obra. Revista Latinoamericana de Psicopatologia Fundamental, São Paulo, v.8, n.3, p.533-539. 2005. 